\title{
Compressive Strength Prediction of Silica Fume mixed Concrete Soaked in Used Engine Oil with a Mathematical Model
}

\author{
Nandini M. Naik ${ }^{\mathrm{a} *}$, Arpa Mukherjee ${ }^{\mathrm{b}}$, Avik Khamaru ${ }^{\mathrm{c}}$, Siddhartha Ojha ${ }^{\mathrm{c}}$, \\ Girish S. Kulkarni ${ }^{\text {d }}$, K. B. Prakash ${ }^{\text {e }}$ \\ ${ }^{a}$ Department of Chemical Engineering K.L.E Dr. M. S Sheshgiri College of Engineering \& Technology, \\ Belgaum, India \\ ${ }^{b}$ Cognizant Technology Solutions, India \\ ${ }^{c}$ Tata Consultancy Services Ltd, India \\ ${ }^{d}$ Department of Technology, Shivaji University Kolhapur, Maharashtra, India \\ ${ }^{e}$ Government Engineering College Haveri, Karnataka, India
}

Received: 11 June 2018; Accepted: 07 October 2018; Published: 08 January 2019

\begin{abstract}
The determination of strength properties i.e., compressive strength (CS) is essential to estimate the load at which the concrete members may crack especially in aggressive environment. The paper reports an experimental investigation on deterioration of used engine oil (UEO) soaked concrete with respect to its strength properties. Also, it is found that this deteriorating effect is lessened with partial replacement of silica fumes (SF). The CS analysis was done with a water-concrete ratio of 0.49 with nine percentage replacements of SF $(0,5,10,15,20,25,30,35,40$ and 45) with water curing and UEO soaking. The soaking in two different liquids was essential in order to throw light on the detrimental effects of UEO on the CS of concrete. The results of the experiments showed that $20 \%$ replacement of SF in concrete was optimum to attain maximum CS. A mathematical model based on Abrams' law has been developed to evaluate the strength characteristics of concrete subjected to UEO soaking. The developed model facilitates the prediction of CS based on curing time in water and soaking time in UEO and also the quantity of SF used. The accuracy of the developed model is evaluated and good agreements with the ground truth values are found.
\end{abstract}

Index Terms: Concrete, silica fumes, compressive strength, used engine oil, mathematical model.

(C) 2019 Published by MECS Publisher. Selection and/or peer review under responsibility of the Research Association of Modern Education and Computer Science.

* Corresponding author.

E-mail address: sneha2bandekar@gmail.com 


\section{Introduction}

Concrete structures usually comes in contact with petroleum products like diesel, petrol, used engine oil and so on, in places like petrol bunks, garages, storage tanks, etc. Either steel or concrete tanks is made use of for the storage of petroleum [1]. Owing to the corrosion hazards, concrete is advisable for storage of petroleum products over metallic products. Drastic decrease in compressive strength of concrete is seen in case of concrete specimen coming in contact with crude oil [2]. Many attempts have been made to increase the strength properties of concrete by the addition of pozzolans. In spite of this, it is seen that concrete quality degrades when it comes in contact with used engine oil (UEO). Hence, efforts to completely avoid or to lessen this degrading effect is crucial.

\section{Related Work}

Matti et al, [3] studied over a period of 3 years, the dynamic modulus of concrete for samples subjected to crude oil soaking. The strength properties of concrete was found to be decreased in this case. A comparison between the physico-chemical effect along oil and water showed that the polar molecules amongst hydrocarbon chain were detrimental to concrete. Water moles are basically tiny dipoles and when acted positively on concrete, it leads to the strengthening of concrete. Hydrocarbon chain is basically non-harmful and non-polar in nature, though issues are found in connection with the hydrophilic part of the problem [4].

An assortment of pozzolan proportions showed increase in strength properties of concrete. However, choosing the right pozzolan with optimum proportion for a specific platform (for instance UEO used in this study) is a very challenging issue. Efforts have been put in promoting the usefulness of industrial wastes or the by-products rich in silica as an admixture to cement. Mineral admixtures as finely ground siliceous material lacks cementitious properties, although reacts with excess $\mathrm{Ca}(\mathrm{OH}) 2$ produced during hydration process. It then converts it to useful cementitious product like C-Si-H (Gel).

The strength properties of concrete are seen to be increased owing to the high pozzolanic activity and void filling of silica fumes. The process comprises of a pozzolanic reaction which converts weak $\mathrm{Ca}(\mathrm{OH}) 2$ crystals into strong $\mathrm{CaSiH}$ (calcium silicate hydrate) gel. The process basically renders significant enhancements in compressive strength as reported in $[5,6,7,8]$. In contrast to reference concrete, a significant enhancement in the strength properties is found for $20 \%$ replacement level (Fig. 1). The drop in excess $\mathrm{Ca}(\mathrm{OH}) 2$ owing to the pozzolanic reaction enhances the durability of concrete by making cement paste more impervious and dense.

Petroleum products degrades the strength properties of concrete. As a result, the concrete structures are deteriorated easily in such an environment $[9,10,11,12,13,14,15]$. Also, petroleum coming in contact with environment poses danger to water bodies [16]. This paper attempts to assess the degrading effect of a petroleum product on concrete and throws light on its minimization with the inclusion of silica fumes.

The rest of the paper is organized as follows. The closely related work is discussed in section II. Section III. briefs the materials and methods of the study. The results are discussed in section IV. The paper concludes in section V.

\section{Materials and Methods}

This section briefs the materials used for the study along with the methodologies adopted.

\subsection{Materials}

\subsubsection{Cement and Silica Fume}

In this research work, 43 grade ordinary Portland cement (OPC) is used for all the concrete mixes. The 
cement used is fresh and has no lumps. Cement's testing is carried on as per IS: 8112-1989 standards. The specific gravity of cement is found to be 3.15 .

Silica fume used in the experimentation is obtained from Elkem laboratory, Navi Mumbai. The chemical properties of silica fume and cement used are given in Table 1. Table 2 gives the detailed physical properties of cement used.

Table 1. Chemical Compositions of Ordinary Portland cement (OPC) and Silica Fume

\begin{tabular}{|c|c|c|}
\hline Composition (\% by mass) & OPC & Silica fume \\
\hline Silica $(\mathrm{SiO} 2)$ & 20.2 & 93.4 \\
\hline Alumina $(\mathrm{A1} 2 \mathrm{O} 3)$ & 4.7 & 0.42 \\
\hline Iron oxide $(\mathrm{FeO} 3)$ & 3 & 0.52 \\
\hline Calcium oxide $(\mathrm{CaO})$ & 61.9 & 1.91 \\
\hline Magnesium oxide $(\mathrm{MgO})$ & 2.6 & - \\
\hline Sodium oxide $(\mathrm{Na} 2 \mathrm{O})$ & 0.19 & 0.25 \\
\hline Potassium oxide $(\mathrm{K} 2 \mathrm{O})$ & 0.82 & 0.79 \\
\hline Sulfur trioxide $(\mathrm{SO} 3)$ & 3.9 & 0.34 \\
\hline Loss on ignition & 1.9 & 2.3 \\
\hline Specific surface area $(\mathrm{m} 2 / \mathrm{kg})$ & $453^{\mathrm{a}}$ & $13,000^{\mathrm{b}}$ \\
\hline
\end{tabular}

a Determined using Blaine's air permeability apparatus.

$\mathrm{b}$ Obtained from the manufacturer of silica fume.

Table 2. Physical properties of ordinary Portland cement

\begin{tabular}{|c|c|c|}
\hline Particulars & As per standard & Experimental result \\
\hline Fineness & Not less than $225 \mathrm{~m} 2 / \mathrm{kg}$ & $308 \mathrm{~m} 2 / \mathrm{kg}$ \\
\hline Soundness & & $1.5 \mathrm{~mm}$ \\
\hline By Le-Chatelier Expn. (mm) & Not more than $10 \mathrm{~mm}$ & 0.07 \\
\hline By Autoclave Expn. (\%) & Not more than 0.8 & 180 \\
\hline Initial & Not less than 30 & 250 \\
\hline Final & Not more than 600 & 36 \\
\hline Compressive strength $(\mathrm{MPa})$ & & 46 \\
\hline 3 days & Not less than 23 & 60 \\
\hline 7 days & Not less than 33 & \\
\hline 28 days & Not less than 43 & \\
\hline
\end{tabular}

\subsubsection{Fine Aggregates}

Locally available sand collected from the bed of river Krishna is used as fine aggregate. Sand is having a fineness modulus 2.38 and conformed to grading zone-II as per IS: 383-1970 specification. Sieve analysis of fine aggregate is given in Table 3 and physical properties tested for fine aggregate are given in Table 4 . The specific gravity of fine aggregate is found to be 2.64 . 
Table 3. Sieve Analysis of fine Aggregate (IS: 383-1970)

\begin{tabular}{|c|c|c|c|c|c|}
\hline $\begin{array}{c}\text { IS Sieve } \\
\text { size }\end{array}$ & $\begin{array}{c}\text { Weight } \\
\text { retained } \\
\text { (grams) }\end{array}$ & $\begin{array}{c}\text { Cumulative } \\
\text { weight retained } \\
\text { (grams) }\end{array}$ & $\begin{array}{c}\text { Cumulative } \\
\% \text { weight } \\
\text { retained }\end{array}$ & $\begin{array}{c}\text { Cumulative } \\
\% \text { passing }\end{array}$ & $\begin{array}{c}\text { Grading } \\
\text { Zone II }\end{array}$ \\
\hline 10 & 0 & 0 & 0 & 100 & 100 \\
\hline 4.75 & 5 & 1 & 5 & 95 & $90-100$ \\
\hline 2.36 & 44 & 45 & 9 & 91 & $75-100$ \\
\hline 1.18 & 30 & 75 & 15 & 85 & $55-90$ \\
\hline $600 \mu \mathrm{m}$ & 50 & 125 & 45 & 55 & $35-59$ \\
\hline $300 \mu \mathrm{m}$ & 185 & 310 & 72 & 28 & $8-30$ \\
\hline $150 \mu \mathrm{m}$ & 120 & 430 & 92 & 8 & $0-10$ \\
\hline Pan & 70 & 500 & & - & - \\
\hline Total & $500 \mathrm{gm}$ & - & 238 & - & - \\
\hline
\end{tabular}

Table 4. Physical Properties of fine Aggregate (IS: 2386-1963)

\begin{tabular}{|c|c|c|}
\hline Properties & Results & Permissible limit as per IS: 2386-1963 \\
\hline Organic impurities & Colorless & Colorless /Straw Color/Dark Color \\
\hline Silt content & $0.7 \%$ & Should not be more than 6-10\% \\
\hline Specific gravity & 2.64 & Should be between the limit $2.6-2.7$ \\
\hline Bulking of sand & $16 \%$ & Should not be more than $40 \%$ \\
\hline Moisture content & $0.65 \%$ & - \\
\hline
\end{tabular}

\subsubsection{Coarse Aggregates}

Aggregates used for the study have fineness modulus of 1.9. The sieve analyses of coarse aggregate are presented in Table 5 while the physical and mechanical properties of the coarse aggregates are presented in Table 6.

Table 5. Sieve analysis of coarse aggregate (IS: 2386-1963)

\begin{tabular}{|c|c|c|c|c|c|}
\hline $\begin{array}{c}\text { IS } \\
\text { sieve } \\
\text { size }\end{array}$ & $\begin{array}{c}\text { Weight } \\
\text { retained } \\
\text { (grams) }\end{array}$ & $\begin{array}{c}\text { Cumulative } \\
\text { weight } \\
\text { retained } \\
\text { (grams) }\end{array}$ & $\begin{array}{c}\text { Cumulative } \\
\% \\
\text { weight } \\
\text { retained }\end{array}$ & $\begin{array}{c}\text { Cumulative } \\
\% \\
\text { passing }\end{array}$ & $\begin{array}{c}\text { ISI } \\
\text { permissible } \\
\text { limit }\end{array}$ \\
\hline $20 \mathrm{~mm}$ & 0 & 0 & 0 & 100 & 100 \\
\hline $12.5 \mathrm{~mm}$ & 0 & 0 & 0 & 100 & $85-100$ \\
\hline $10 \mathrm{~mm}$ & 1860 & 1860 & 93 & 7 & $0-20$ \\
\hline $4.75 \mathrm{~mm}$ & 93 & 1953 & 97.65 & 2.35 & $0-5$ \\
\hline Pan & 47 & 2000 & - & - & - \\
\hline Total & 2000 & - & 190.65 & - & - \\
\hline
\end{tabular}


Table 6. Physical and Mechanical Properties of Coarse Aggregate (IS: 2386-1963)

\begin{tabular}{|c|c|c|}
\hline Properties & Results & Permissible limit as per IS: 2386-1963 \\
\hline Impact value & $15.50 \%$ & Should not be more than 30\% used for concrete \\
\hline Crushing value & $25.00 \%$ & $\begin{array}{c}\text { Should not be more than 30\% for surface course } \\
\text { and 45\% other than wearing course }\end{array}$ \\
\hline Specific gravity & 2.90 & In between range 2.6-2.8 \\
\hline Moisture content & $0.16 \%$ & - \\
\hline
\end{tabular}

\subsubsection{Sand}

Locally available sand of specific gravity 2.64 and coarse aggregates of $(d \max =20 \mathrm{~mm})$ were utilized.

\subsubsection{Water}

Clean potable water taken from the city sources is utilized exclusively for both during concreting and curing processes.

\subsubsection{Used engine oil}

Properties of used engine oil are shown in the Table 7. The engine oil used for soaking the concrete specimens is taken from automobile service station. Properties of used engine oil are shown in the Table 7.

Table 7. Properties of used engine oil

\begin{tabular}{|c|c|}
\hline Properties & Results \\
\hline Kinematics viscosity at $40{ }^{\circ} \mathrm{c}$ & 111.32 \\
\hline Kinematics viscosity at $100{ }^{\circ} \mathrm{c}$ & 17.83 \\
\hline Viscosity index $^{\circ}$ & 99 \\
\hline Flash Point, $^{\circ} \mathrm{c}$ & 230 \\
\hline Pour Point, $^{\circ} \mathrm{c}$ & -10 \\
\hline TBN & - \\
\hline Sulfated ash, wt $\%$ & 4.5 \\
\hline Specific gravity & 0.928 \\
\hline
\end{tabular}

\subsection{Methods}

The specimens were separated into two categories (Group A and B). Group A specimens were left without any interruptions in water itself for another 90 days. Simultaneously, the Group B specimens were immersed in UEO for the same interval of time. Both the specimens were tested for their respective compressive strengths as per IS specifications. Both the classes of specimens were tested for their strength properties performed on $7^{\text {th }}, 14^{\text {th }}, 28^{\text {th }}, 40^{\text {th }}, 52^{\text {nd }}$ and $90^{\text {th }}$ days. Silica fume mixed concrete was used with two variants in the assessment of strength properties, few samples were water cured (designated as Group A samples) and the 
rest were soaked in UEO (Group B samples). 189 concrete beams with varying proportions of silica fume admixture were cast and water cured for 28 days. On the $28^{\text {th }}$ day, 3 cubes from the 9 samples (with different percentage of silica fume ranging between $0-45 \%$ ) were taken and their respective compressive strength was measured. Totally 27 out of 189 samples were tested here. Then, 135 samples were soaked in the UEO (Group B) and the remaining 27 samples were water cured (Group A). At specific intervals (14, 28, 40, 52, 90 days) the compressive strength strengths of Group B specimens were assessed. In case of Group A, the test was conducted for the $28^{\text {th }}$ and $90^{\text {th }}$ day only (the reason being, most of the hydration takes place within 28 days and later the changes in compressive strengths are marginal).The compressive strengths of both the Groups A and B were compared against their corresponding time intervals. Entire concrete cube with its shape intact was used for compressive strength analysis by using Compressive Testing Machine (CTM). The compressive strength of the entire samples is summarized in Fig. 1.

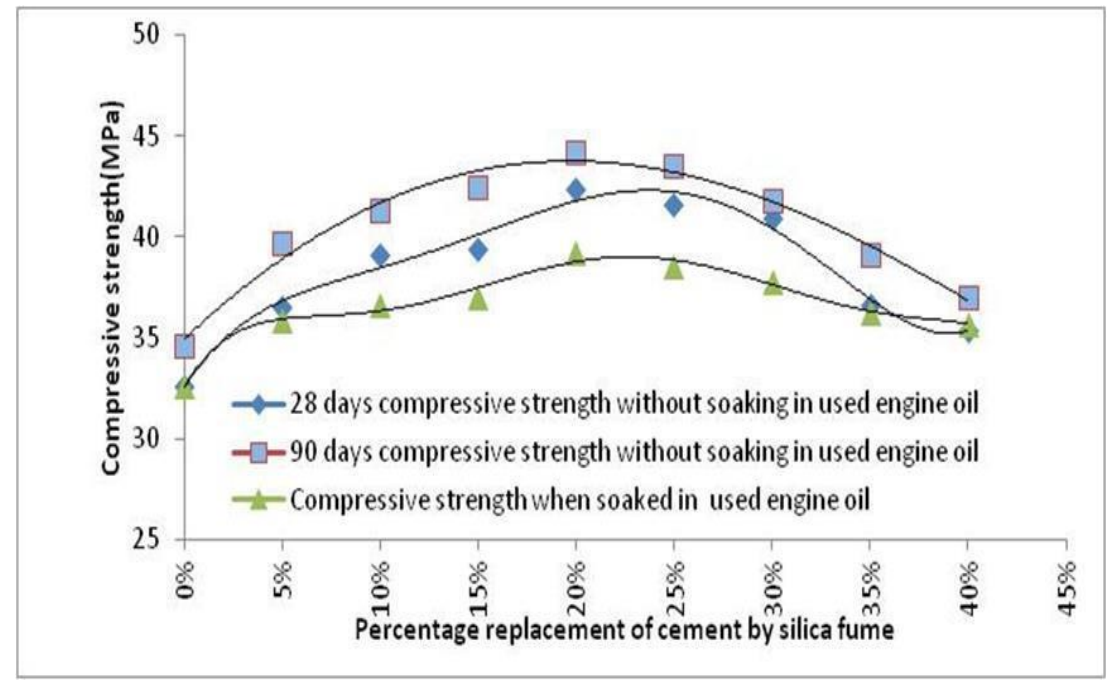

Fig.1. Compressive Strength of Concrete Mixed with Silica Fume. Note the Variations in Compressive Strengths Due to Soaking in used Engine Oil.

\section{Results and Discussions}

The experimental results can be better explained using a mathematical model. The primary factors affecting the compressive strength of concrete in our study are water, SF, UEO and curing/soaking time. We deal with each of the factors individually by using regression analysis and modeling. Fig. 2 gives a brief idea of the modeling process involved.

According to Abrams' law, the compressive strength and water-to-cement ratio follows an inverse relationship given by equation $1[8]$.

$$
\left.\left.f c=A / B^{((} w / c\right)\right)
$$

Where A and B are the constant coefficients and w/c denotes water-to-cement ratio. The curing time of water affects the compressive strength and obeys a logarithmic relation governed by equation 2 [8], 


$$
f c=b+\operatorname{alog}(t)
$$

Where $\mathrm{a}$ and $\mathrm{b}$ are constant coefficients. When applied to our study, equation 2 can be rewritten as equation 3 (with no SF taken, see Fig. 3),

$$
f_{c}=0.5545 \log (t)+28.292
$$

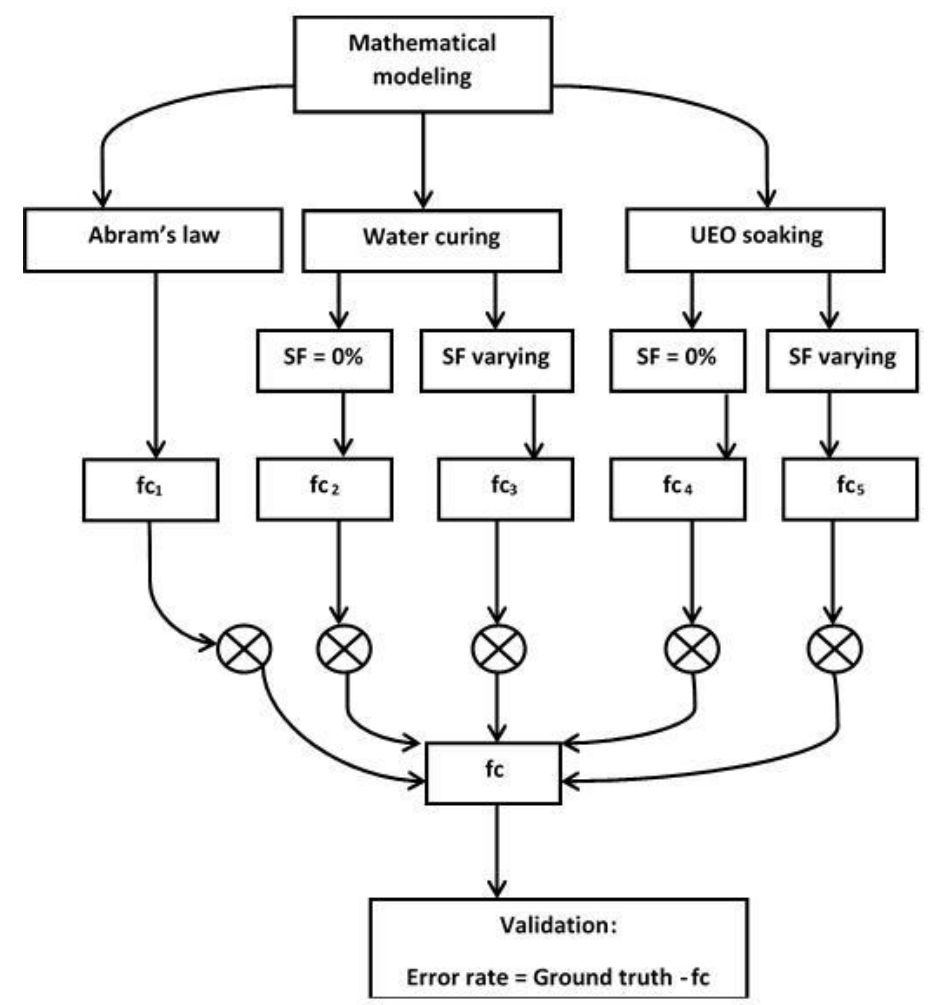

Fig.2. Depiction of Overall Workflow

Based on the principles of regression we derive a two-degree equation (equation 4) for the compressive strength based on the varying percentages of SF used ( $s$ ) with water curing time kept constant (for 90 days).

$$
R f c=C f c-G f c \quad f c=-0.0196 s^{2}+0.8167 s+35.217
$$

On similar grounds, we derive the relation for UEO soaking of concrete with $0 \%$ SF to study the effect of soaking time $(t)$ of concrete in UEO (equation 5).

$$
f c=0.0000 t^{2}-0.017 s+32.384
$$




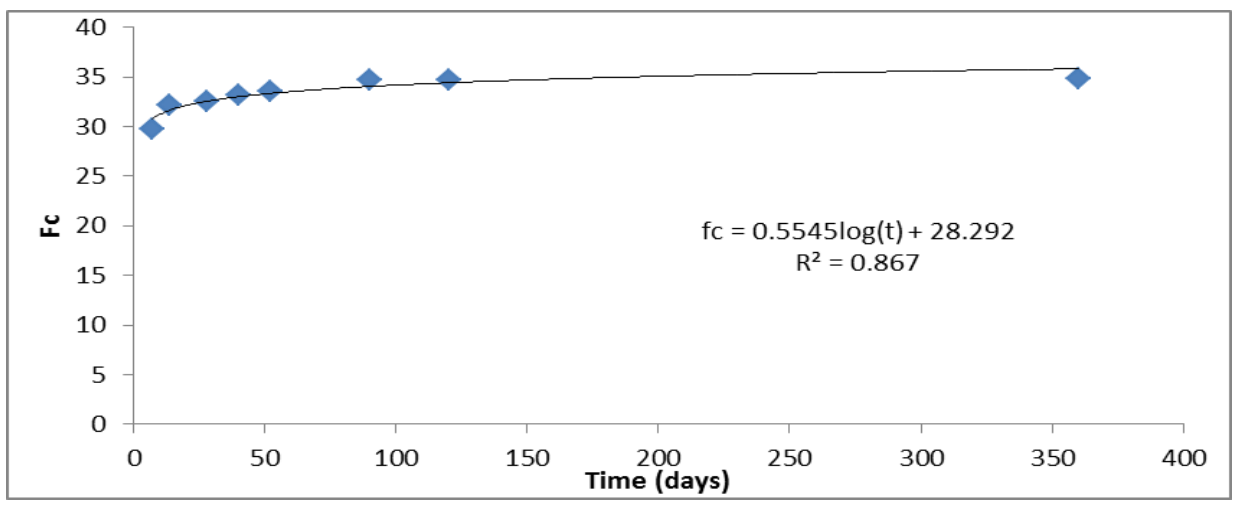

Fig.3. Relationship between Compressive Strength with time of Curing in Water (days)

Finally, we derive the relation for compressive strength of concrete with UEO soaking for different variations of SF for 90 days of soaking time (see equation 6).

$$
f c=-0.0119 s^{2}+0.5197 s+32.844
$$

The overall relationships can be combined with considered variables as follows,

$$
\begin{aligned}
& f c=\frac{A}{B^{\left(\frac{W}{e}\right)}}+F \times \log \left(-0.0119 s^{2}+0.5197 s+32.844\right) \times(0.5545 \log (t)+28.292)^{C} \\
& \times\left(-0.0196 s^{2}+0.8167 s+35.217\right)^{D} \\
& \times\left(0.0000 t^{2}-0.017 s+32.384\right)^{E} \\
& \times\left(-0.0119 s^{2}+0.5197 s+32.844\right)^{F} \\
& \log (f c)=\log (A)-\log (B) \times(w / c) \\
& +C \times \log \left(0.5545 \log ^{2}(t)+28.292\right) \\
& +D \times \log \left(-0.0196 s^{2}+0.8167 s+35.217\right) \\
& +E \times \log \left(0.0000 t^{2}-0.017 s+32.384\right) \\
& +F \times \log \left(-0.0119 s^{2}+0.5197 s+32.844\right)
\end{aligned}
$$


where A, B, C, D, E and F can be determined with multiple linear regressions.

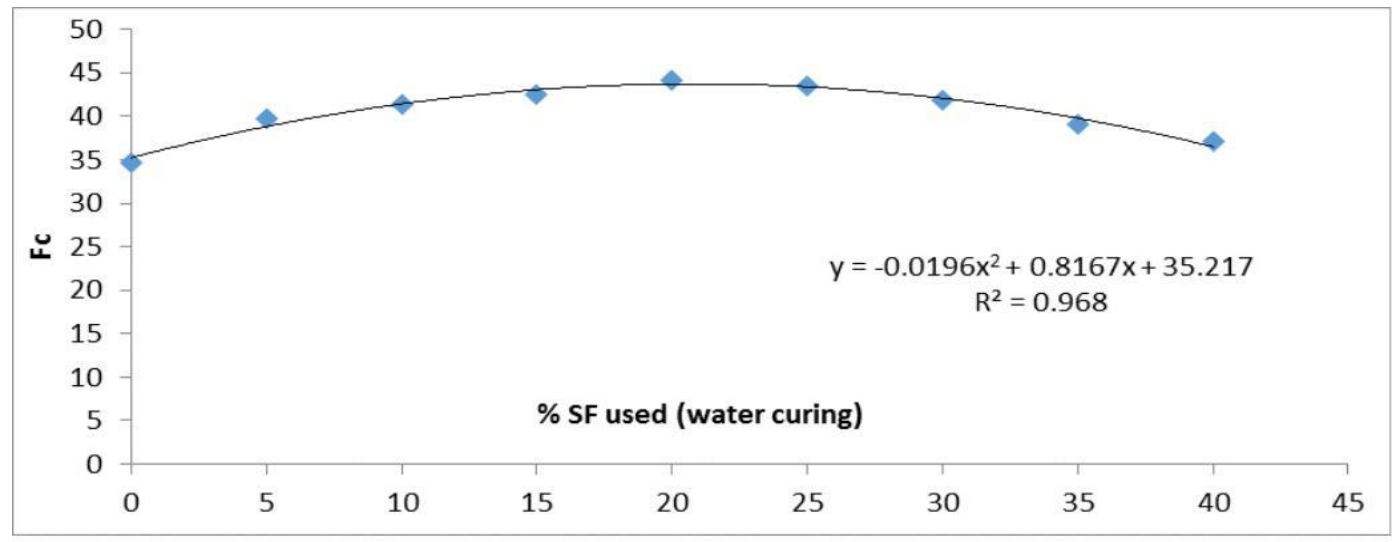

Fig.4. Relation between SF used and Compressive Strength (Water Curing for 90 days)

In order to validate the above equation, we find the residuals given in equation (9), where $\mathrm{fc}$ is the compressive strength, $t$ is the time of soaking/curing, w/b is water to cement ratio and $\mathrm{s}$ is the percentage of SF used. Applying logarithms on both sides, we have,

$$
\log (f c)=\log (A)-\log (B) \times(w / c)
$$

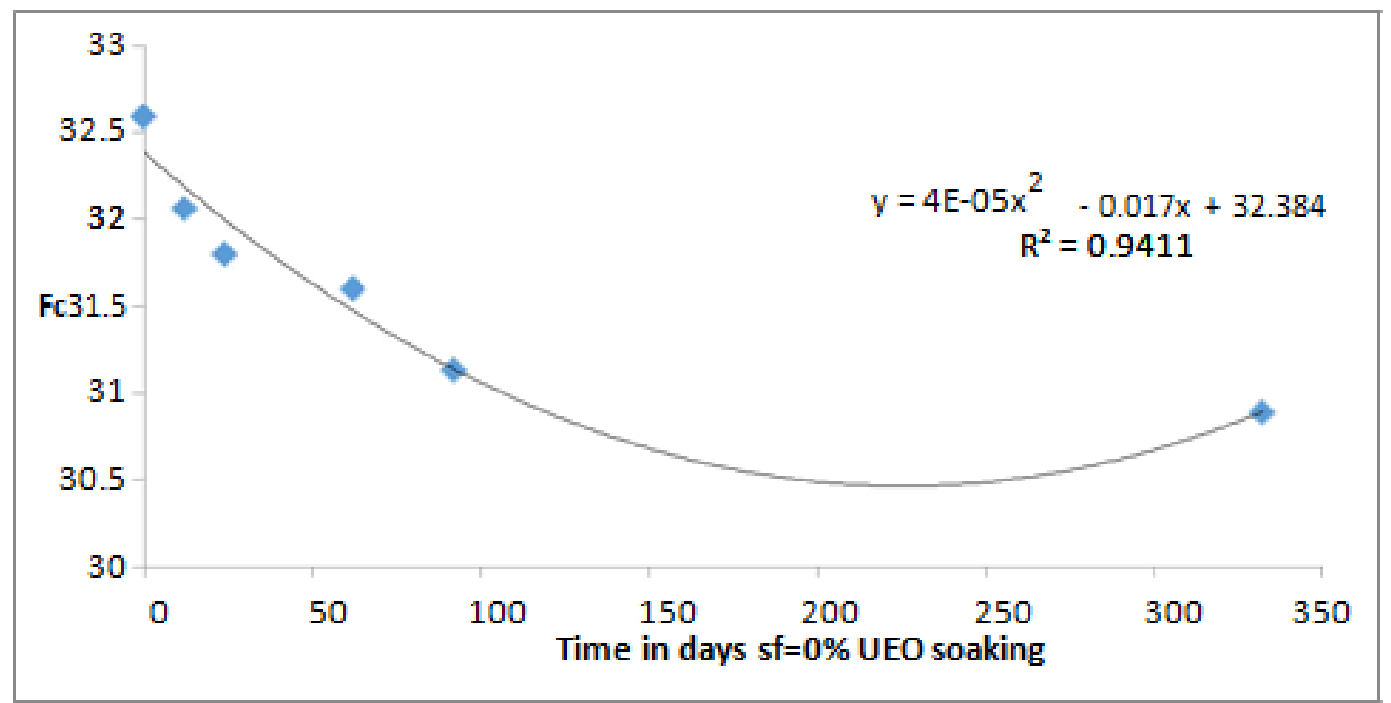

Fig.5. Relation between Compressive Strength and Concrete (with 0\% SF) in UEO Soaking. 


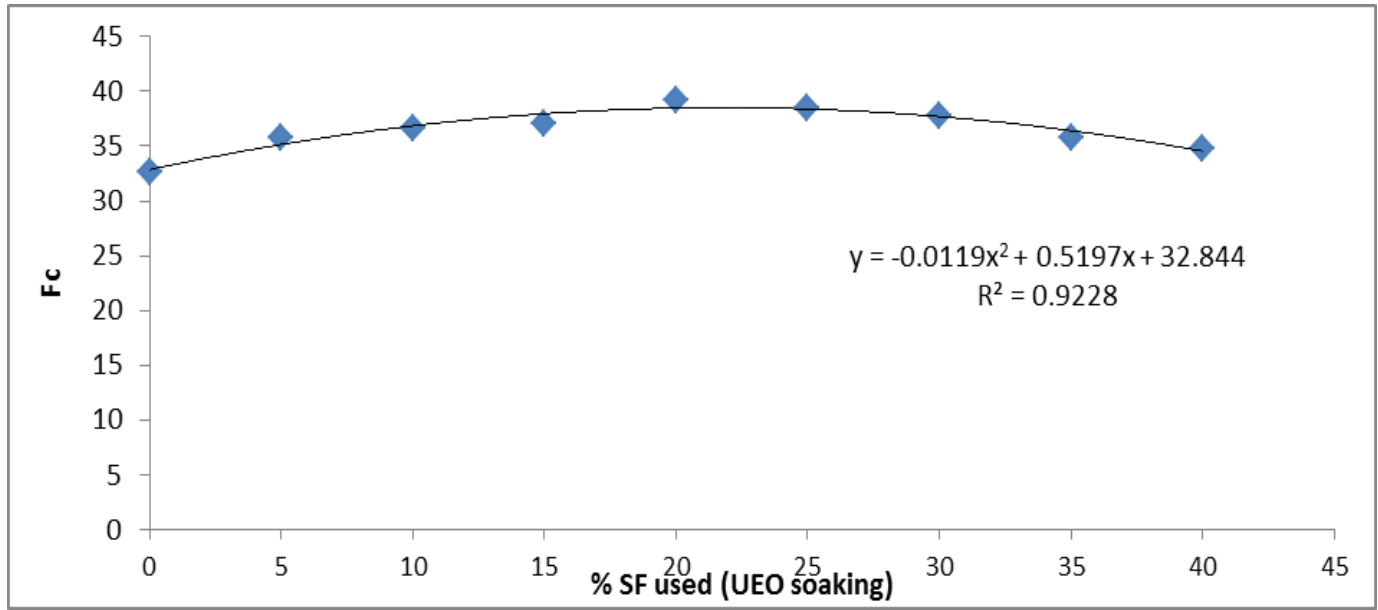

Fig.6. Relation between Compressive Strength and SF used (90 days UEO soaking)

$$
R f c=C f c-G f c
$$

where $R$ corresponds to the residual values obtained after taking the difference of calculated values $(C)$ and the ground truth (observed values) $G$ of the compressive strength $f c$. The residuals are plotted in Fig. 7 . This diagram shows that the maximum percentage error in the predicted values of $f c \pm 2 \%$.

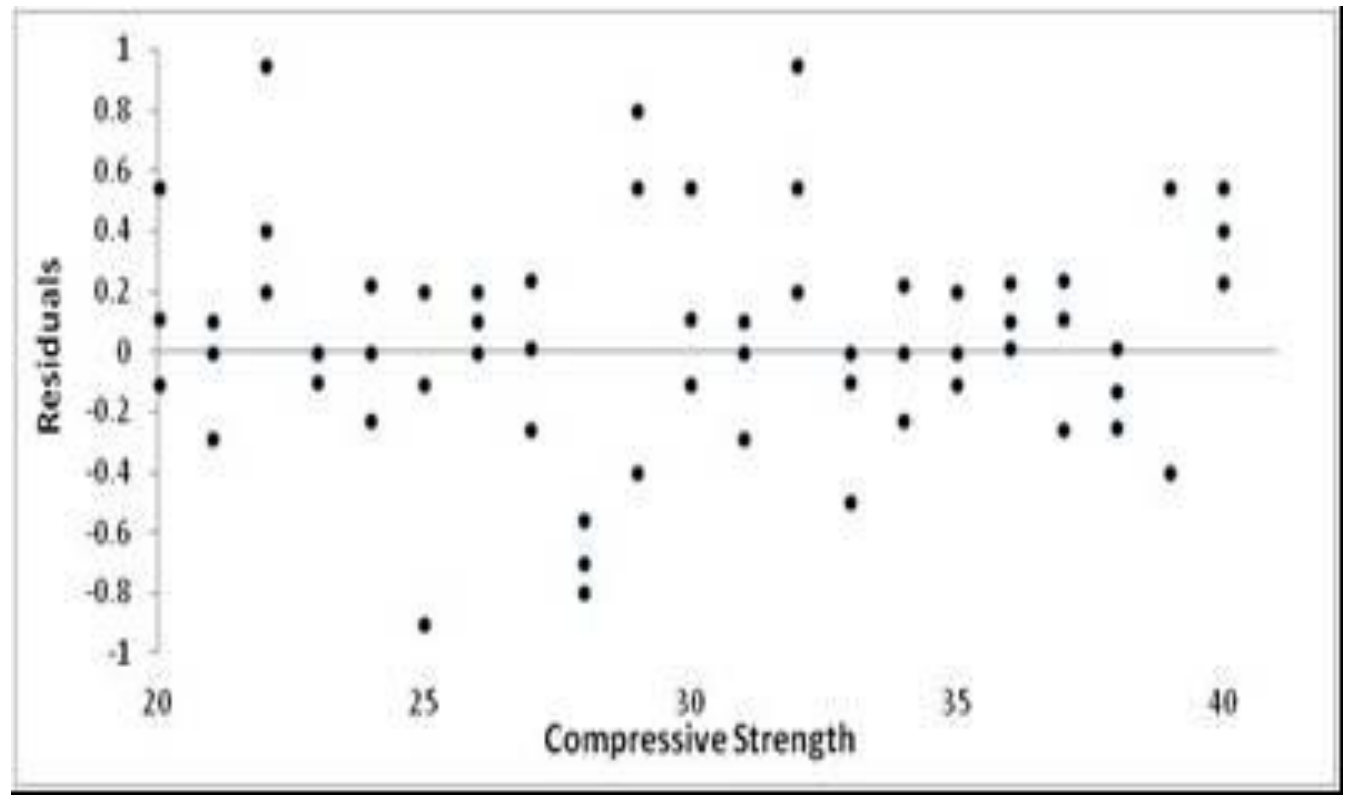

Fig.7. Residuals for Compressive Strength (equation 9) 


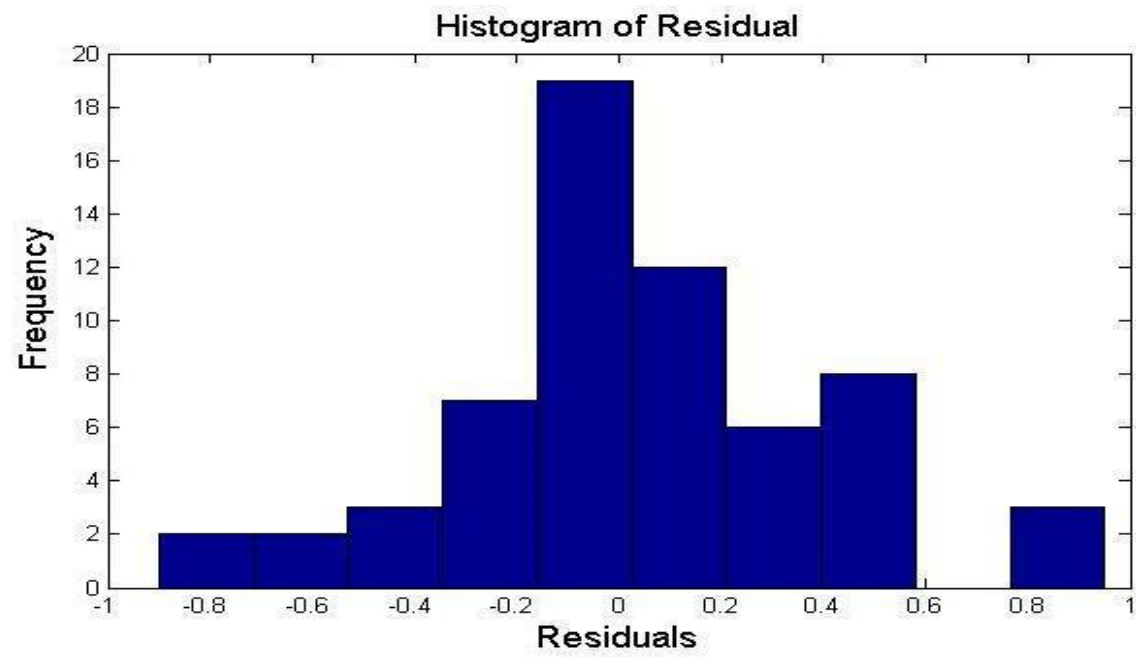

Fig.8. Histogram of Residuals Computed for the Residuals (equation (9)).

Fig. 8 shows the histogram for the residuals computed (Average \pm SD: 0.0502 \pm 0.3709 ). It can be observed that the mean and maximum values of the residuals in the histogram lie near zero.

\section{Conclusions and Future Scope}

The degree of degradation of UEO on concrete with respect to compressive strength were assessed and found that the negative effect on strength properties were considerably less for silica fume mixed concrete. Thus, it aids in the use of industrial waste product to reduce pollution. The mathematical model designed for the prediction of compressive strength of concrete soaked in used engine oil was in good agreement with the ground truth. As a future scope we would like to extend our model to incorporate different pozzolans and soaking time in different petroleum by-products into our model.

\section{Acknowledgements}

The authors are indebted to KLE Dr. M. S. Sheshagiri College of Engineering and Technology, Belgaum, and Shivaji University, Kolhapur; for all the crucial amenities provided for the experimentation.

\section{References}

[1] Nuruddin M.F.,et al(2008). Effect of Used Engine Oil on MIHRA Concrete, A New Material In The Construction Industry. United Kingdom Malaysia Engineering Conference, vol. 28, No. 3, pp. 398-11.

[2] Wasiu O. Ajagbe, Olusola S. Omokehinde, Gabriel A. Alade, Oluwole A. Agbede, (2012). Effect of Crude Oil Impacted Sand on compressive strength of concrete. Construction and Building Materials 26 (2012) 9-12, Elsevier. doi: 10.1016/j.conbuildmat.2011.06.028

[3] M.A. Matti, (1983). Effect of oil soaking on the dynamic modulus of concrete. International Journal of Cement Composites and Lightweight Concrete, Volume 5, Issue 4, Pages 277-282, Elsevier. doi:10.1016/0262-5075(83)90069-6 
[4] T.Z. Blaszczynski, 'Concrete in contact with crude oil', STATYBA-CIVIL ENGINEERING, No. 2(6), 1996, pp.13-17.

[5] Bhanja, S., \& Sengupta, B. (2005). Influence of silica fume on the tensile strength of concrete. Cement and Concrete Research, 35(2005), 743-747.

[6] Biswal, K. C., \& Sadang, S. C. (2010). Effect of superplasticizer and silica fume on properties of concrete. In Proceedings of International Conference on Advances in Civil Engineering.

[7] Katkhuda, H., Hanayneh, B., \& Shatarat, N. (2009). Influence of silica fume on high strength of light weight concrete. World Academy of Science, Engineering and Technology, 58, 781-788.

[8] Popovics, S. (1998). Strength and related properties of concrete a quantitative approach. New York, NY: Wiley.

[9] Naik, Nandini M., Girish S. Kulkarni, and K. B. Prakash. "Assessment of the Deterioration of used Engine Oil Soaked Fly ash Concrete and its Analysis using Automated SEM Analysis." (2016). I.J. Engineering and Manufacturing. MECS Publishers. DOI: 10.5815/ijem.2016.03.01.

[10] Girish, S. K., K. B. Prakash, and M. N. Nandini. "Negative impact of diesel and used engine oil soaking on the compressive strength of concrete." International journal of advance research in sciences and engineering 3 (2014): 01.

[11] Naik, Nandini M., Girish S. Kulkarni, and K. B. Prakash. "Effect of solid wastes on the characteristics behaviour of petroleum products soaked concrete-A Review." (2013).

[12] Abdul Ahad, Ramzi B., and Azad A. Mohammed. "Compressive and tensile strength of concrete loaded and soaked in crude oil." (2000).

[13] Faiyadh, F. I. "Bond characteristics of oil saturated concrete." International Journal of Cement Composites and Lightweight Concrete 7.2 (1985): 115-131.

[14] Diab, Hesham. "Compressive strength performance of low-and high-strength concrete soaked in mineral oil." Construction and Building Materials 33 (2012): 25-31.

[15] Svintsov, A. P., T. SF Gamal, and E. E. Shumilin. "Effect of mineral and vegetable oil on deformation properties of concrete." RUDN Journal of Engineering Researches 18.2 (2017): 245-253.

[16] Naik, Nandini M., Girish S. Kulkarni, and K. B. Prakash. "Analysis and Treatment of Water Contaminated by Petroleum Products." (2014). MECS Publishers.

\section{Authors' Profiles}

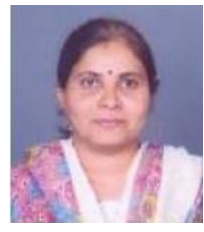

Kolhapur.

Dr. Nandini M Naik has graduated in Chemical Engineering from SIT, Tumkur and completed her post-graduation in Chemical Engineering from Shivaji University, Kolhapur. She is currently working as Associate Professor in Chemical Engineering Department, K.L.E Dr. M. S. Shesagiri College of Engineering and Technology, Belgaum, Karnataka. She is having a teaching experience of over 19 years, and is a has completed her $\mathrm{PhD}$ from Environmental Science and Engineering, Department of Technology, Shivaji University,

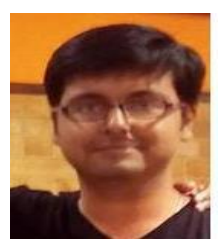

Arpa Mukherjee has completed his bachelor of technology from Asansol Engineering College, Kolkata, India. He is currently working at Cognizant Technology Solutions, India. He carried out this work as part of a college project during his bachelor of technology studies. His work interests include data analysis, signal processing and software engineering. 


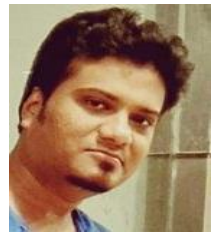

Avik Khamaru has completed his bachelor of technology from Asansol Engineering College, Kolkata, India. He is currently working at Tata Consultancy Services Ltd, India. He carried out this work as part of a college project during his bachelor of technology studies. His work interests include robotics, signal processing and software engineering.

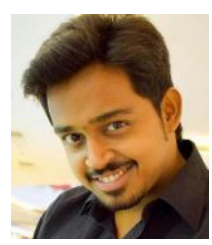

Siddhartha Ojha has completed his bachelor of technology from Techno India College, Kolkata, India. He is currently working at Tata Consultancy Services Ltd, India. He carried out this work as part of a college project during his bachelor of technology studies. His work interests include signal processing, machine learning and software engineering.

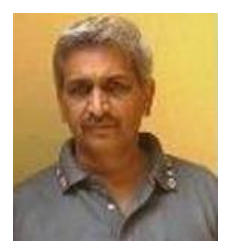

Girish. S. Kulkarni, has graduated in Civil Engineering and post graduated in Environmental Engineering from Shivaji University, Kolhapur and Ph.D in Environmental Engineering and Technology from Walchand College of Engineering, Sangli. He is currently working as Professor in Environmental Science and Technology, Department of Technology, Shivaji University Kolhapur, Maharashtra. He has published and presented many technical papers in international and national conference.

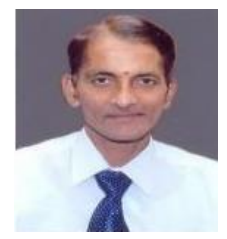

Dr. K. B. Prakash, has graduated in Civil Engineering from National Institute of Engineering Mysore and post graduated in Structural Engineering and Ph.D degree from Walchand College of Engineering, Sangli. He is currently working as Professor and Head in Civil Engineering Department and Principal of Government Engineering College, Haveri, Karnataka. He has 27 years of teaching experience and 2 years of industrial experience. He has published around 200 technical papers in International/National Journals and proceedings of International/ National conferences.

How to cite this paper: Nandini M. Naik, Arpa Mukherjee, Avik Khamaru, Siddhartha Ojha, Girish S. Kulkarni, K. B. Prakash,"Compressive Strength Prediction of Silica Fume mixed Concrete Soaked in Used Engine Oil with a Mathematical Model", International Journal of Engineering and Manufacturing(IJEM), Vol.9, No.1, pp.64-76, 2019.DOI: 10.5815/ijem.2019.01.06 